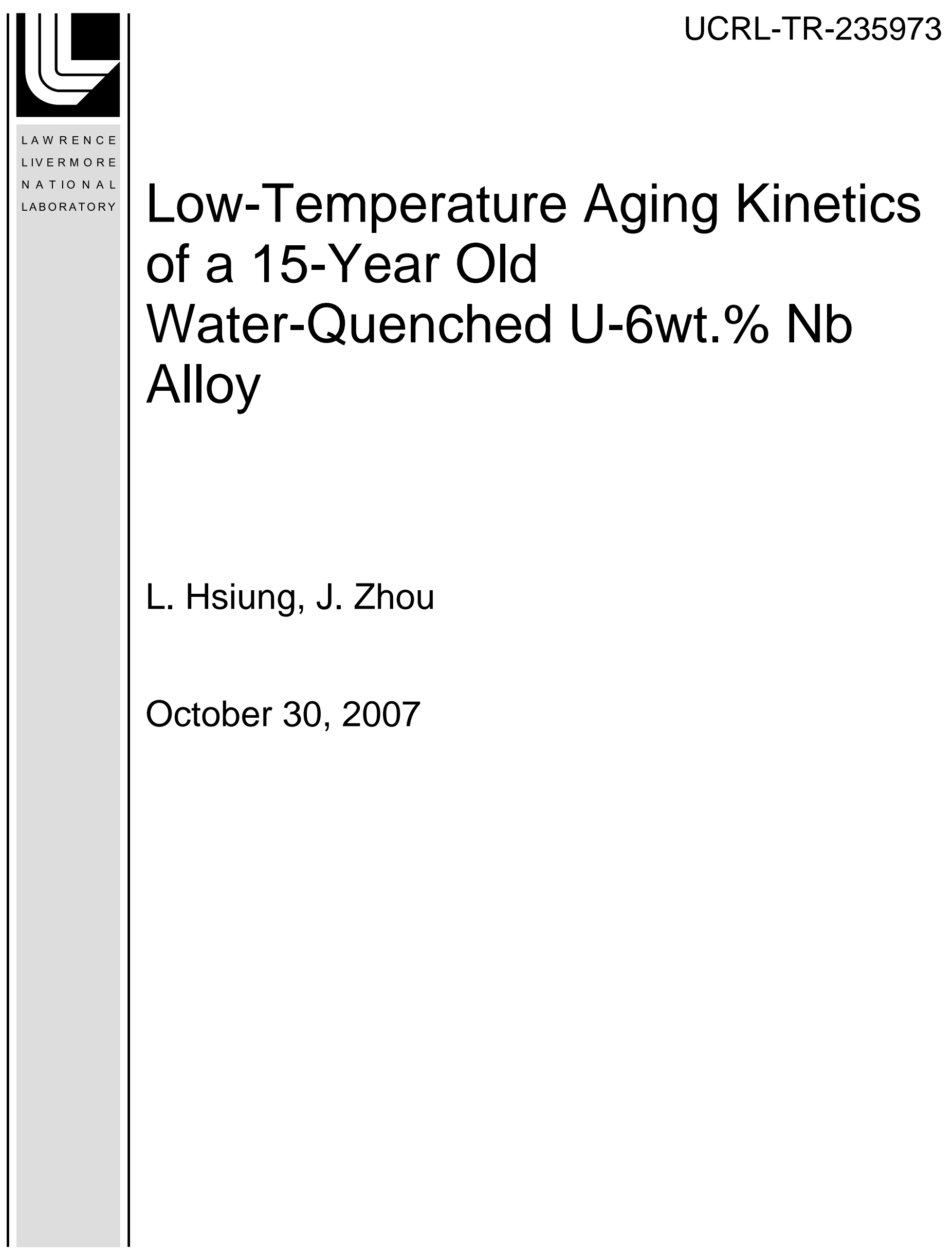


This document was prepared as an account of work sponsored by an agency of the United States government. Neither the United States government nor Lawrence Livermore National Security, LLC, nor any of their employees makes any warranty, expressed or implied, or assumes any legal liability or responsibility for the accuracy, completeness, or usefulness of any information, apparatus, product, or process disclosed, or represents that its use would not infringe privately owned rights. Reference herein to any specific commercial product, process, or service by trade name, trademark, manufacturer, or otherwise does not necessarily constitute or imply its endorsement, recommendation, or favoring by the United States government or Lawrence Livermore National Security, LLC. The views and opinions of authors expressed herein do not necessarily state or reflect those of the United States government or Lawrence Livermore National Security, LLC, and shall not be used for advertising or product endorsement purposes.

This work performed under the auspices of the U.S. Department of Energy by Lawrence Livermore National Laboratory under Contract DE-AC52-07NA27344. 


\title{
Low-Temperature Aging Kinetics of a 15-Year Old Water-Quenched U-6wt.\% Nb Alloy
}

\author{
Luke Hsiung and Jikou Zhou \\ Chemistry, Materials, Earth, and Life Sciences Directorate \\ Material Science and Technology Division
}

\section{Introduction}

It is well known that $\mathrm{U}-6 \mathrm{wt} . \% \mathrm{Nb}(\mathrm{U}-14 \mathrm{at} . \% \mathrm{Nb})$ alloy has a microstructure containing martensitic phases supersaturated with $\mathrm{Nb}$ that can be obtained by rapid quenching the alloy from $\gamma$ (bcc)-field solid solution to room temperature. The high cooling rate forces the $\gamma$-phase solid solution to transform to variants of the low-temperature $\alpha$ (orthorhombic) phase in which $\mathrm{Nb}$ is forced to retain in the supersaturated solid solution. However, the crystal lattice of supersaturated solution formed by rapid quenching is in unstable conditions and is severely distorted since the solubility of $\mathrm{Nb}$ in the $\alpha$ phase at room temperature is nearly zero under an equilibrium condition. Two variant phases, a monoclinic distortion of $\alpha$ phase that is designated as $\alpha^{\prime \prime}$ martensite and a tetragonal distortion of $\gamma$ phase that is designated as $\gamma^{0}$ phase, can form in the as-quenched alloy, as shown in Fig. 1.
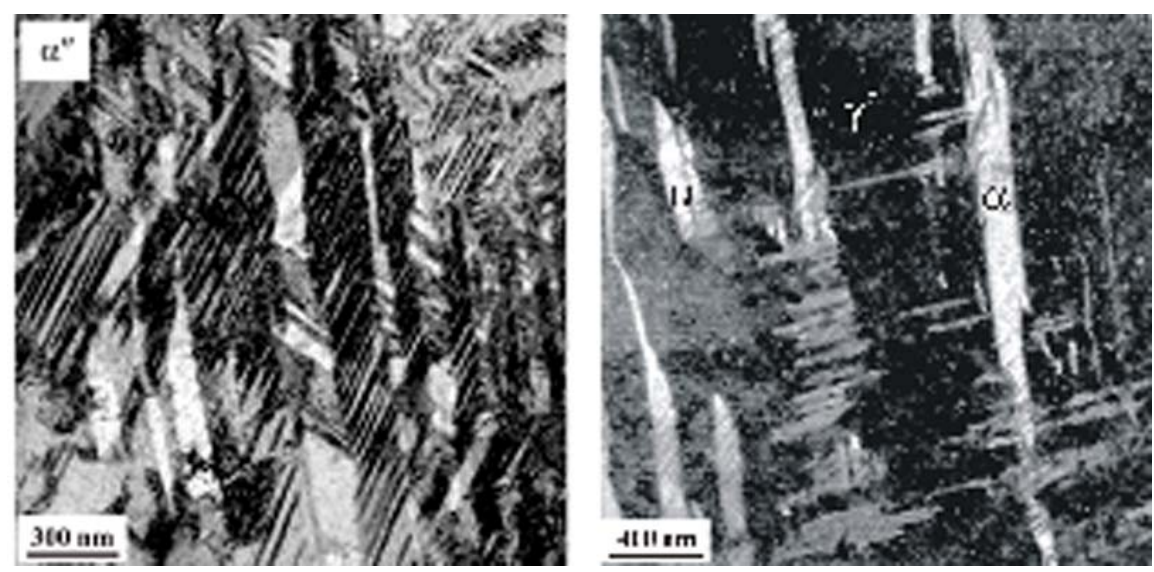

Fig. 1. Bright-field TEM images show the microstructure of a WQ-U6Nb alloy containing both heavily twinned $\alpha^{\prime \prime}\left(\sim 90\right.$ vol.\%) and $\gamma^{\circ}(\sim 10$ vol.\%) martensites. 
We have learned from our previous TEM studies on the low-temperature aging of a water-quenched $\mathrm{U} 6 \mathrm{Nb}$ (WQ-U6Nb) alloy that there are two possible transformation pathways for phase decomposition of the alloy supersaturated with 14 at. $\%$ of $\mathrm{Nb}$ upon aging at temperatures below $200^{\circ} \mathrm{C}$, i.e., (1) supersaturated solid solution $\alpha^{\prime \prime} \rightarrow$ spinodal decomposition $\rightarrow \alpha_{1}$ (Nb-lean) $+\alpha_{2}$ (Nb-rich) at $200^{\circ} \mathrm{C}$ and (2) supersaturated solid solution $\alpha^{\prime \prime} \rightarrow$ spinodal ordering $\rightarrow \alpha_{\text {po }}^{\prime \prime}$ (partially ordered phase $) \rightarrow$ phase decomposition and precipitation $\rightarrow \alpha(\mathrm{U})+\alpha_{0}\left(\mathrm{U}_{3} \mathrm{Nb}\right)$ at ambient temperatures [1]. The mechanisms for the spinodal transformation occurred at $200^{\circ} \mathrm{C}$ and the spinodal ordering occurred at ambient temperatures are quite similar; both are caused by the composition modulation of $\mathrm{Nb}$ except that the wavelength $(\lambda \approx 3 \mathrm{~nm})$ of modulation for spinodal decomposition is larger than that $(\lambda \approx 0.5 \mathrm{~nm})$ of modulation for the spinodal ordering, as illustrated in Fig. 2. Since the $\mathrm{Nb}$ modulation for the spinodal ordering can occur within the unit cell of $\alpha^{\prime \prime}$ phase through the nearest jumps of atoms along the [001] direction, the degree of long-range order (S) increases from 0 to 0.16 as a result of the $\mathrm{Nb}$ modulation, as illustrated in Fig. 3. As we accelerated the ordering transformation by thermal heating a 15 -year old alloy at $200^{\circ} \mathrm{C}$, decomposition of the $\alpha^{\prime \prime}$ po phase into $\alpha(\mathrm{U})$ and a fully ordered $\alpha_{\mathrm{o}}\left(\mathrm{U}_{3} \mathrm{Nb}\right)$ phase occured, as shown in Fig. 4. Figure 5 shows the results of microhardness measurement and TEM analysis of the microstructural evolution in the 15 -old alloy samples thermally heated at $200^{\circ} \mathrm{C}$. Here, it can be clearly seen that the $\alpha_{\text {po }}^{\prime \prime}$ phase with a swirl-shape feature of antiphase boundaries (APBs) vanishes upon heating with the formation of $\mathrm{U}_{3} \mathrm{Nb}$ precipitates, which gives rise to the increase of microhardness (precipitation hardening). Figure 6 shows the changes of tensile properties of the 15old alloy thermally heated at $200^{\circ} \mathrm{C}$. It can be readily seen that in addition to the increase of tensile strength (precipitation hardening), the ductility reduces from $\sim 40 \%$ to $\sim 14 \%$ after heating for 96 hours. In view of these adverse changes in tensile properties upon aging, we accordingly pursued a 
precipitation kinetics study on the 15-year old WQ-U6Nb alloy in order to develop an empirical timetemperature-transformation model for predicting the remaining lifetime of the WQ-U6Nb alloy in the stockpile.

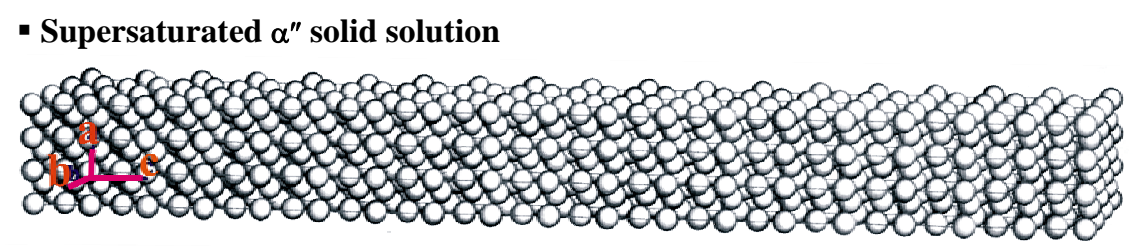

- Spinodal decomposition at $200^{\circ} \mathrm{C}: \lambda=3 \mathrm{~nm}$

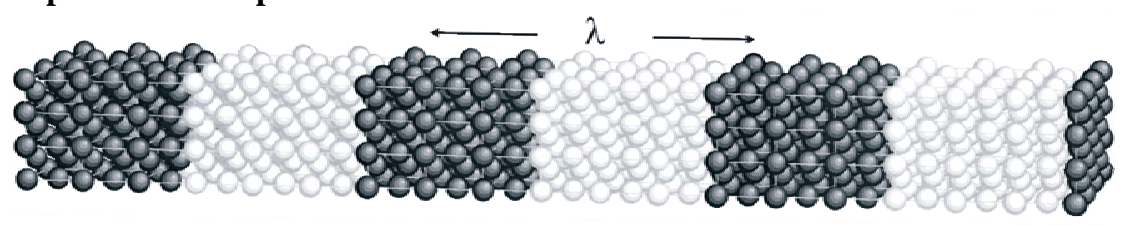

- Spinodal ordering at room temperature: $\lambda=0.5 \mathrm{~nm}$

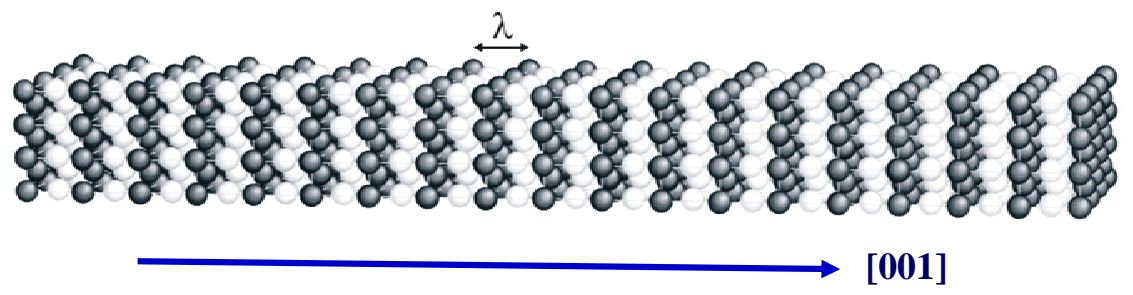

Fig. 2. Schematic illustrations show the temperature dependency of the wavelength of composition modulation, in which the dark spheres represent the $\mathrm{Nb}$-enriched atomic positions.

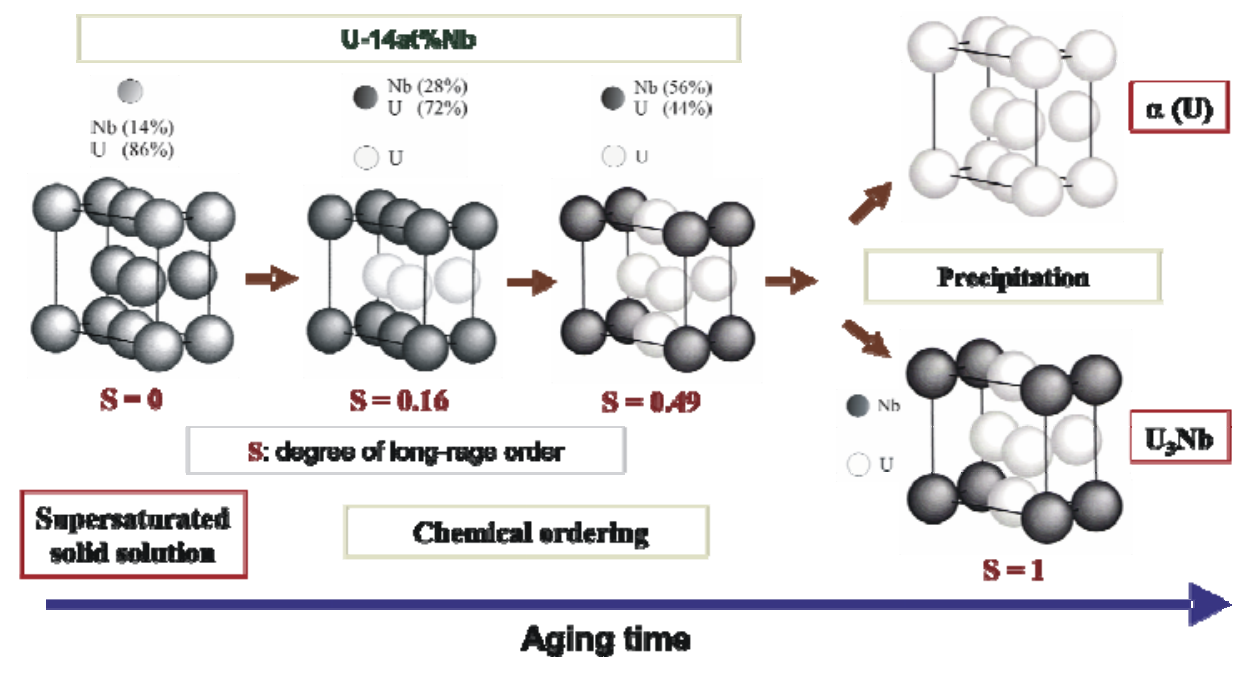

Fig. 3. Schematic illustration of the transformation sequence for an order-disorder transformation in the 15-year old, naturally aged WQ-U6Nb alloy. 


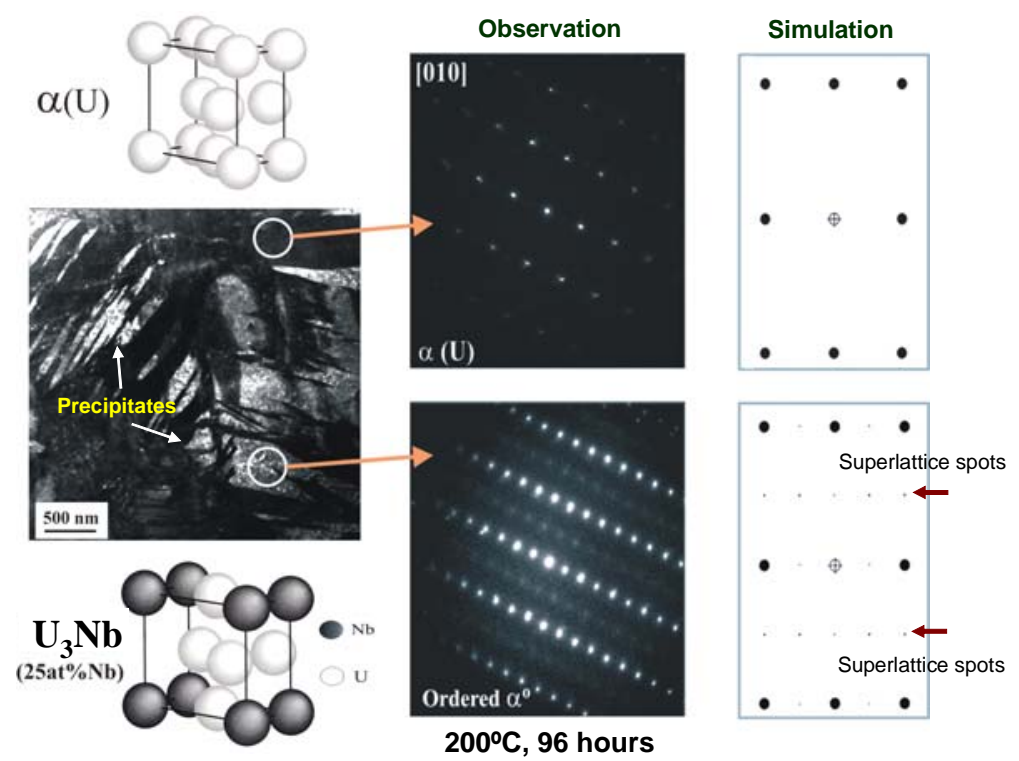

Fig. 4. The partially ordered $\alpha_{0}$ " phase decomposes into $\alpha(U)$ and ordered $U_{3} \mathrm{Nb}$ phases, as identified by observed and simulated electron diffraction patterns, when the 15 -year old alloy was heated at $200^{\circ} \mathrm{C}$.

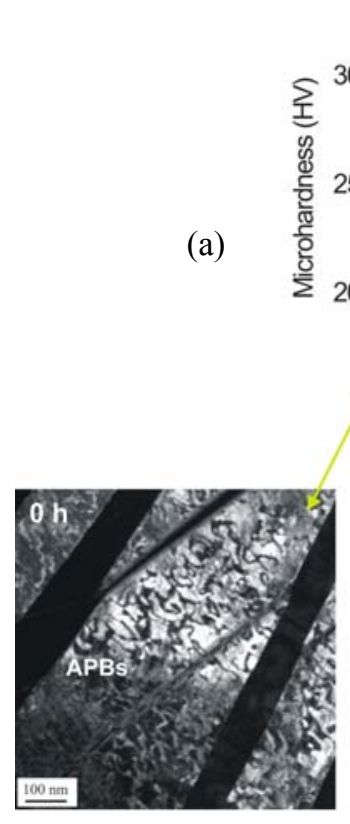

(b)

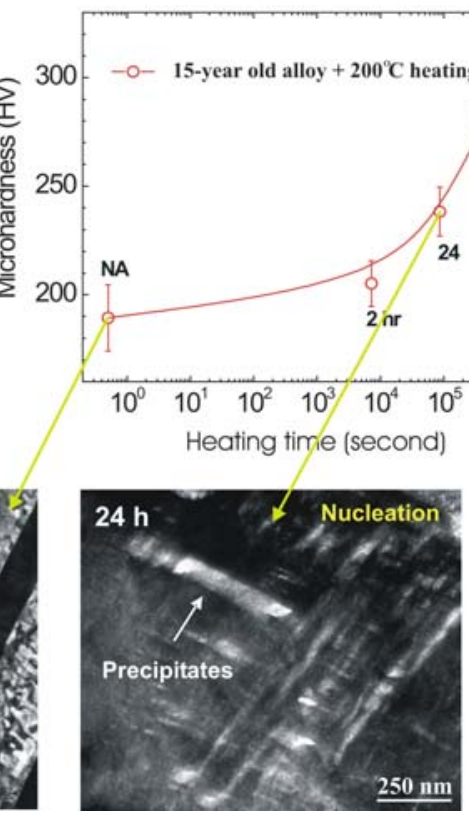

(c)

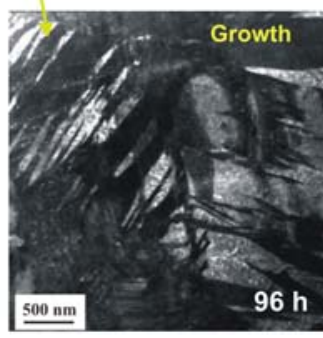

(d)

Fig. 5. (a) Precipitation hardening occurred during thermal heating of the 15-year old alloy at $200^{\circ} \mathrm{C}$. Dark-field TEM images show (b) APBs in the 15-year old alloy, (c) fine precipitates formed in the alloy after heating for 24 hours, and (d) relatively higher volume fraction of precipitates formed in the alloy after heating for 96 hours. Notice in (c) and (d) that the APBs observed in (a) vanished after aging at $200^{\circ} \mathrm{C}$. 


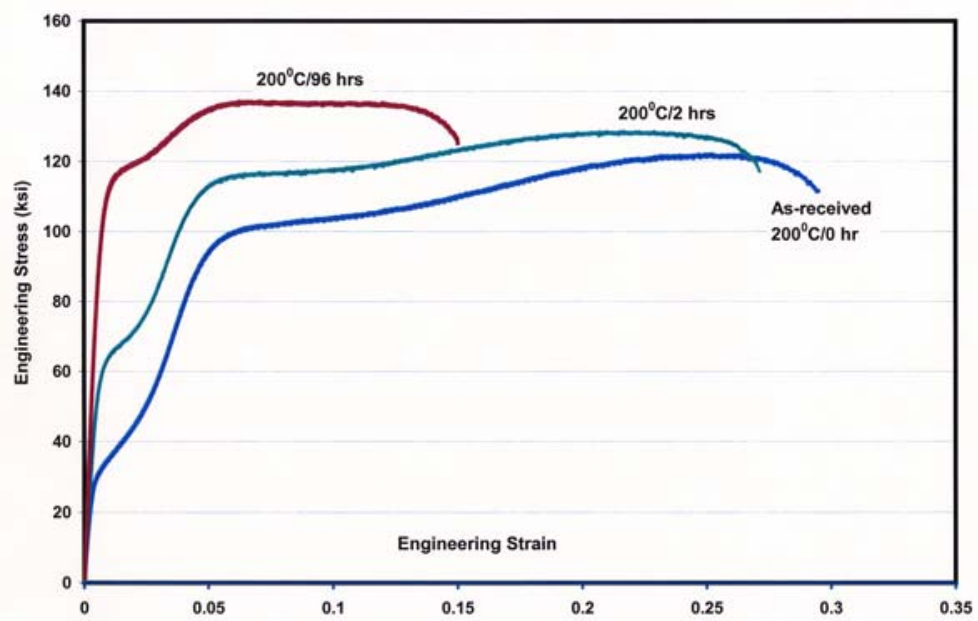

Fig. 6. Thermal aging of the 15 -year old $\mathrm{WQ}-\mathrm{U} 6 \mathrm{Nb}$ at $200^{\circ} \mathrm{C}$ results in an increase of the yield strength (precipitation hardening) and a significant reduction of the tensile ductility.

\section{Experimental approach and methodology}

\subsection{Precipitation kinetics}

The nucleation rate $\left(\mathrm{N}^{*}\right)$ of a $\alpha_{\mathrm{o}}\left(\mathrm{U}_{3} \mathrm{Nb}\right)$ phase formed in the partially ordered $\alpha^{\prime \prime}$ po matrix can be expressed as: $N^{*}=n_{s} v_{0} \rho N_{v} \exp \left[-\left(\Delta G_{a}+\Delta G_{c}\right) / k T\right](1)$, where $N^{*}$ is in units of nuclei per unit volume per unit time, $\mathrm{n}_{\mathrm{s}}$ is the number of matrix atoms on the surface of a nucleus, $v_{\mathrm{o}}$ is the frequency of jumps, $\rho$ is the direction factor of jumps, $N_{v}$ is the number of atoms per unit volume, $k$ is Boltzman constant, $\Delta \mathrm{G}_{\mathrm{a}}$ is the activation energy for diffusion, and $\Delta \mathrm{G}_{\mathrm{c}}$ is the critical energy barrier for nucleation. Let $\mathrm{K}_{\mathrm{v}}$ (the frequency factor) $=\mathrm{n}_{\mathrm{S}} \mathrm{V}_{\mathrm{o}} \rho \mathrm{N}_{v}$, thus eqn (1) can be rewritten as: $\mathrm{N}^{*}=\mathrm{K}_{\mathrm{V}} \exp [-$ $\left.\left(\Delta \mathrm{G}_{\mathrm{a}}+\Delta \mathrm{G}_{\mathrm{c}}\right) / \mathrm{kT}\right](2)$.

After a nucleus appears, it can further reduce its free energy by continuous growth. The solute atoms can be transferred by diffusion in several steps: (a) the migration of solute atoms through the parent phase, (b) the migration of solute atoms across the interface boundary, and (c) the migration of solute atoms into the nucleus. For an one-dimensional needle (or plate) growth mechanism, the ratelimiting step is to lengthen the $\alpha_{\mathrm{o}}\left(\mathrm{U}_{3} \mathrm{Nb}\right)$ plates. Since it is diffusion control, it obeys a parabolic 
growth law, and the lengthening of a lath $[\mathrm{L}(\mathrm{t})]$ can be expressed as: $\mathrm{L}(\mathrm{t})=\mathrm{C} \exp \left[-\Delta \mathrm{G}_{\mathrm{a}} / 2 \mathrm{kT}\right]\left(\mathrm{t}-\mathrm{t}_{\mathrm{o}}\right)^{1 / 2}$ (3), where $\mathrm{C}$ is a constant, and $\mathrm{t}_{\mathrm{o}}$ is the instant of time when the nucleus forms.

Nucleation actually continues at all times during the precipitation process. In the time $\mathrm{dt}_{\mathrm{o}}$, $\mathrm{n}^{*} \mathrm{dt}_{\mathrm{o}}$ nuclei are formed, where $\mathrm{n} *$ is in units of nuclei per unit time. The total volume $\left(\mathrm{V}_{\mathrm{T}}\right)$ which has transformed since the beginning of the precipitation $\left(t_{0}\right)$ can be expressed as follows: $V_{T}=C n^{*}$ $\int\left(t-t_{O}\right)^{1 / 2} \mathrm{dt}(4)$. It is noted that the maximum volume of $\alpha_{\mathrm{o}}\left(\mathrm{U}_{3} \mathrm{Nb}\right)$ precipitates can be reached during the precipitation process is $\sim 56$ vol. $\%$; the transformation can be considered to be $100 \%$ completed when the maximum vol.\% of precipitates is reached. If $\mathrm{Y}$ is the percentage transformed, and $\mathrm{dx}$ is a fraction of transformed solution from the untransformed solution $(1-\mathrm{Y})$, then we have (1 - Y) $d x=d Y(5)$, where $d Y$ is the increment of fraction transformed.

Integrating the above equation, we obtain: $\mathrm{Y}=1-\mathrm{e}^{-\mathrm{x}}(6)$, and $\mathrm{x}=\mathrm{V}_{\mathrm{T}} / \mathrm{V}_{0}=\mathrm{C}\left(\mathrm{n}^{*} / \mathrm{V}_{0}\right)$ $\int\left(t-t_{O}\right)^{1 / 2} \mathrm{dt}$. Thus, $\mathrm{Y}=1-\exp \left[-\mathrm{C} \mathrm{N}^{*} \int\left(t-t_{O}\right)^{1 / 2} \mathrm{dt}\right]$ (7). By inserting eqn (3) into (7), it becomes $y=1-\exp \left(-0.5 \mathrm{C} \mathrm{N}^{*} \mathrm{t}\right)(8)$, and by inserting eqn (2) into eqn (8), it becomes $\mathrm{Y}=1-\exp \left\{\mathrm{C}_{0}\right.$ $\left.\exp \left[-\left(1.5 \Delta \mathrm{G}_{\mathrm{a}}+\Delta \mathrm{G}_{\mathrm{c}}\right) / \mathrm{kT}\right] \mathrm{t}\right\}$ (9). This has the form of Avrami equation [2]: $\mathrm{Y}=1-\exp \left(-\mathrm{Kt}^{\mathrm{n}}\right)(10)$ and $\mathrm{K}=\mathrm{C}_{0} \exp \left[-\left(\Delta \mathrm{G}_{\mathrm{a}}+\Delta \mathrm{G}_{\mathrm{c}}\right) / \mathrm{kT}\right](11)$, where $\mathrm{K}$ is a rate constant that depends on both nucleation and growth rates, and $\mathrm{n}$ is a constant that depends on the growth mechanism of precipitate. On the assumption that the time $(\mathrm{t})$ to a given percentage transformed $\mathrm{Y}(\%)$ is inversely proportional to the rate of nucleation $(\mathrm{K})$, it is possible to write $\ln \mathrm{t}=1.5 \Delta \mathrm{G}_{\mathrm{a}} / \mathrm{kT}+\Delta \mathrm{G}_{\mathrm{c}} / \mathrm{kT}-\ln \mathrm{C}_{0}(12)$. A schematic representation of the ln $\mathrm{t}$ vs. 1/T plot is shown in Fig. 7. By differentiating eqn (12) with respect to 1/T, and since $\Delta \mathrm{G}_{\mathrm{a}}$ is constant with $\mathrm{T}$ but $\Delta \mathrm{G}_{\mathrm{c}}$ (which decreases with increasing undercooling) is not, it becomes: $\mathrm{d}(\ln \mathrm{t}) / \mathrm{d}(1 / \mathrm{T})=1.5 \Delta \mathrm{G}_{\mathrm{a}} / \mathrm{k}+\Delta \mathrm{G}_{\mathrm{c}} / \mathrm{k}+\left[\mathrm{d} \Delta \mathrm{G}_{\mathrm{c}} / \mathrm{d}(1 / \mathrm{T})\right] / \mathrm{kT}(13)$.

The percentage transformed, $\mathrm{Y}(\%)$, can be approximately measured from the change of 
microhardness according to law of mixtures: $\mathrm{H}_{t}=\mathrm{H}_{\mathrm{m}} \mathrm{V}_{\mathrm{m}}+\mathrm{H}_{\mathrm{p}} \mathrm{V}_{\mathrm{p}}$ and $\mathrm{V}_{\mathrm{m}}+\mathrm{V}_{\mathrm{p}}=1$, where, $\mathrm{V}_{\mathrm{m}}$ is the volume fraction of matrix, $\mathrm{V}_{\mathrm{p}}$ is the volume fraction of precipitate, $\mathrm{H}_{\mathrm{t}}$ is the microhardness of transformed alloy, $\mathrm{H}_{\mathrm{m}}$ is the microhardness of the alloy without precipitation, and $\mathrm{H}_{\mathrm{p}}$ and $\mathrm{H}_{\mathrm{f}}$ are the microhardness of the alloy with a specific volume fraction of precipitate and the $100 \%$ transformed alloy with $\mathrm{V}_{\mathrm{p}} \approx 56 \%$, respectively. The microhardness of the transformed alloy increases proportionally with the increasing volume of precipitates and reaches a maximum value when the alloy contains a maximum volume fraction of $\mathrm{U}_{3} \mathrm{Nb}$ precipitates; the microhardness starts to decrease when coarsening of the precipitates starts. Thus, the percentage transformed, $Y(\%)$, can be approximately evaluated as: $\mathrm{Y}(\%) \approx\left[\left(\mathrm{H}_{\mathrm{t}}-\mathrm{H}_{0}\right) /\left(\mathrm{H}_{\mathrm{f}}-\mathrm{H}_{0}\right)\right](14)$, where $\mathrm{H}_{\mathrm{t}}$ is the hardness of partially transformed material, $\mathrm{H}_{0}$ and $\mathrm{H}_{\mathrm{f}}$ are the values of hardness corresponding to $0 \%$ and $100 \%$ transformed, respectively.

Since at low temperatures the activation energy for nucleation is small $\left(\Delta \mathrm{G}_{\mathrm{c}} \approx 0\right)$ as a result of large undercooling, thus eqn $(13)$ reduces to $\mathrm{d}(\ln \mathrm{t}) / \mathrm{d}(1 / \mathrm{T}) \approx 1.5 \Delta \mathrm{G}_{\mathrm{a}} / \mathrm{k}(15)$. That is, the low-temperature part of time-temperature-transformation curve, as schematic illustration shown in Fig. 7, is linear, and the equation for the slope is: $\ln \mathrm{t}=1.5 \Delta \mathrm{G}_{\mathrm{a}} / \mathrm{kT}-\ln \mathrm{C}_{0}(16)$, and $\ln \mathrm{C}_{0}$ is the intercept on the $\ln \mathrm{t}$ vs. $1 / \mathrm{T}$ plot. $\Delta \mathrm{G}_{\mathrm{a}}$ can therefore be determined from the slope of eqn (16). Given the $\Delta \mathrm{G}_{\mathrm{a}}$ and $\mathrm{C}_{0}$ determined by the graphical method, shown in Fig. 7, and a theoretical value of $n=1$ [4] for the growth mechanism of needles and plates of finite dimensions, as shown in Fig. 5, the lowtemperature kinetics of precipitation reaction in the 15-year old alloy can therefore be modeled using Avrami approach represented by eqn (10). 


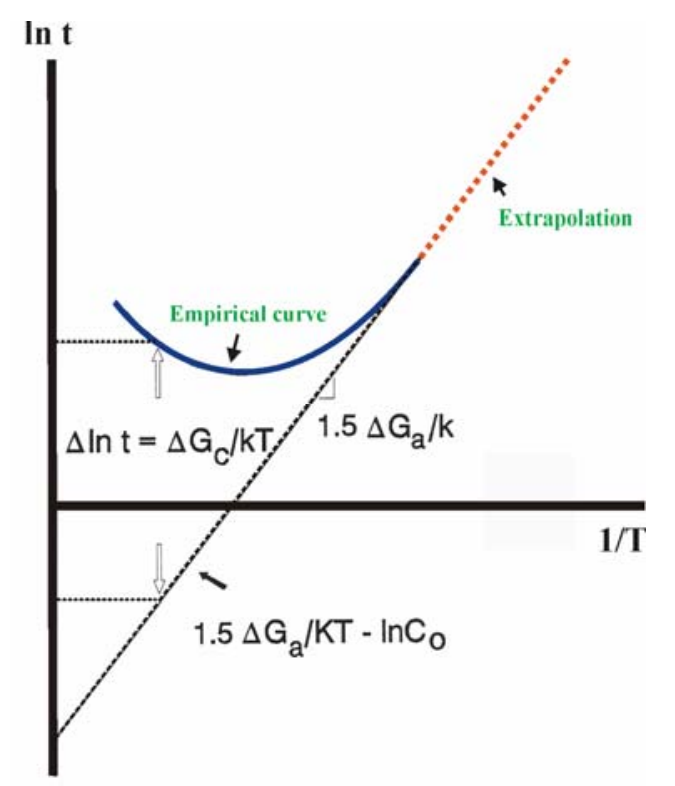

Fig. 7. Graphical meathod of determining the diffusion energy for diffusion $\left(\Delta \mathrm{G}_{\mathrm{a}}\right)$ and activation energy for nucleation $\left(\Delta \mathrm{G}_{\mathrm{c}}\right)$ from an inverse time-temperature-transformation (TTT) diagram.

\subsection{Experimental procedure}

A stockpile-returned (15-year old) alloy part was employed for the aging kinetics study. The major advantage of employing this alloy part is that the early stages of the precipitation process, i.e., spinodal ordering has been completed. We can therefore focus the study on the precipitation kinetics of the $\alpha_{\text {po }}^{\prime \prime}$ $\rightarrow \alpha(\mathrm{U})+\alpha_{0}\left(\mathrm{U}_{3} \mathrm{Nb}\right)$ reaction. Thermal aging experiments (Table 1) were conducted at temperatures ranging between $188^{\circ} \mathrm{C}$ and $250^{\circ} \mathrm{C}$. Microhardness measurements were then carried out to determine the volume fraction of $\mathrm{U}_{3} \mathrm{Nb}$ precipitate in the post-aged alloy samples according to eqn (14). The percentage transformed $\mathrm{Y}(\%)$ of the 15 -year old alloy at temperatures below $188^{\circ} \mathrm{C}$ can therefore be extrapolated from the kinetic model obtained from this study based on eqn (15) by obtaining the value of activation energy for diffusion, $\Delta \mathrm{G}_{\mathrm{a}}$, using the graphical method illustrated in Fig. 7.

\section{Results and Discussion}

Results of microhardness values measured from thermal aging of the 15-year old WQ-U6Nb alloy at $188{ }^{\circ} \mathrm{C}, 200{ }^{\circ} \mathrm{C}, 212{ }^{\circ} \mathrm{C}, 235{ }^{\circ} \mathrm{C}$, and $250{ }^{\circ} \mathrm{C}$ are summarized in Table 1 . The curves of 
microhardness versus aging time are shown in Fig. 8a together with the curve of microhardness obtained from the new WQ-U6Nb alloy thermally aged at $200{ }^{\circ} \mathrm{C}$, which was reported previously [1], for a comparison. These microhardness curves obtained from thermal aging of the 15-year old WQ-U6Nb alloy samples clearly show the dependence of microhardness change on aging temperature. However, it is noted that the peak microhardness value was reached for the aging experiment at $250^{\circ} \mathrm{C}$ only since much longer aging periods are required to reach the peak value due to a sluggish kinetics at lower temperatures. The 15 -year old WQ-U6Nb alloy sample has a microhardness value of $\sim 190 \mathrm{HV}$, and the peak microhardness value can be achieved from the heating is $\sim 340 \mathrm{HV}$.

The thermal aging time (t) required to reach the microhardness value corresponding to the percentage transformaed, $\mathrm{Y}(\%)$, by $20 \%, 50 \%$, and $90 \%$ are evaluated according to the results of aging experiments that were conducted at temperatures (T) of $200{ }^{\circ} \mathrm{C}, 212{ }^{\circ} \mathrm{C}, 235^{\circ} \mathrm{C}$, and $250^{\circ} \mathrm{C}$. It is noted that data obtained from the experiment at $188{ }^{\circ} \mathrm{C}$ are not used here since a furnace calibration is in need for the accuracy of the recorded temperature at $188^{\circ} \mathrm{C}$. The results were then re-plotted as $\ln \mathrm{t}$ versus $1 / \mathrm{T}$, which is shown in Fig. 8b, in which a linear equation with a constant slope but with various intercept values (C) was obtained through line fitting; the equation can be expressed as:

$$
\ln t=11342 \frac{1}{T}-C
$$

It is noted that the R-Square values for the three fitting lines are greater than 0.98 (a perfect fitting would have a value of unit) suggesting that the fitting is pretty good. For a nucleation-controlled precipitation process, the equation has the following form [2]:

$$
\ln t=\frac{\Delta G_{a}}{R T}-C,
$$


The activation energy for diffusion $\left(\Delta \mathrm{G}_{\mathrm{a}}\right)$ is evaluated to be $22.5 \mathrm{kcal} / \mathrm{mol}$. However, for a nucleation and growth process, the equation is in the form of eqn (16):

$$
\ln t=1.5 \frac{\Delta G_{a}}{R T}-C,
$$

The activation energy diffusion is then evaluated to be $15.0 \mathrm{kcal} / \mathrm{mol}$. Accordingly, the aging times required to transform the 15 -year old WQ-U6Nb alloy by $20 \%, 25 \%, 50 \%, 80 \%$, and $90 \%$ at temperatures $30^{\circ} \mathrm{C}, 50{ }^{\circ} \mathrm{C}, 75^{\circ} \mathrm{C}$, and $100{ }^{\circ} \mathrm{C}$ can be predicted and are summarized in Table 2 together with a ductility reduction ( $\sim 5 \%)$ measured from an alloy sample transformed by $50 \%$.

Table 1: Microhardness values for heating of the 15-year old WQ-U6Nb alloy.

\begin{tabular}{|c|c|c|c|}
\hline \multirow{2}{*}{$\begin{array}{c}\text { Aging } \\
\text { Temp }\left({ }^{\circ} \mathrm{C}\right)\end{array}$} & \multirow[b]{2}{*}{ Time (Hr.) } & \multicolumn{2}{|c|}{ Vickers Microhardness (HV) } \\
\hline & & Average & Std. Dev. \\
\hline \multicolumn{2}{|c|}{ Naturally Aged } & 189.4 & 15.2 \\
\hline \multirow{6}{*}{188} & 2 & 195.8 & 9.2 \\
\hline & 24 & 221.0 & 10.7 \\
\hline & 96 & 237.3 & 13.4 \\
\hline & 240 & 257.1 & 10.2 \\
\hline & 720 & 271.2 & 7.4 \\
\hline & 1680 & 292.7 & 10.9 \\
\hline \multirow{4}{*}{200} & 2 & 205.2 & 10.5 \\
\hline & 24 & 238.3 & 11.2 \\
\hline & 96 & 274.0 & 11.3 \\
\hline & 240 & 293.0 & 9.7 \\
\hline \multirow{3}{*}{212} & 2 & 215.2 & 6.6 \\
\hline & 24 & 254.3 & 11.0 \\
\hline & 96 & 292.9 & 9.8 \\
\hline \multirow{2}{*}{235} & 24 & 276.5 & 12.9 \\
\hline & 96 & 318.0 & 12.1 \\
\hline \multirow{6}{*}{250} & 2 & 251.3 & 20.8 \\
\hline & 8 & 269.8 & 36.4 \\
\hline & 32 & 298.2 & 19.4 \\
\hline & 96 & 325.0 & 11.9 \\
\hline & 110 & 336.4 & 13.7 \\
\hline & 140 & 333.1 & 17.1 \\
\hline
\end{tabular}



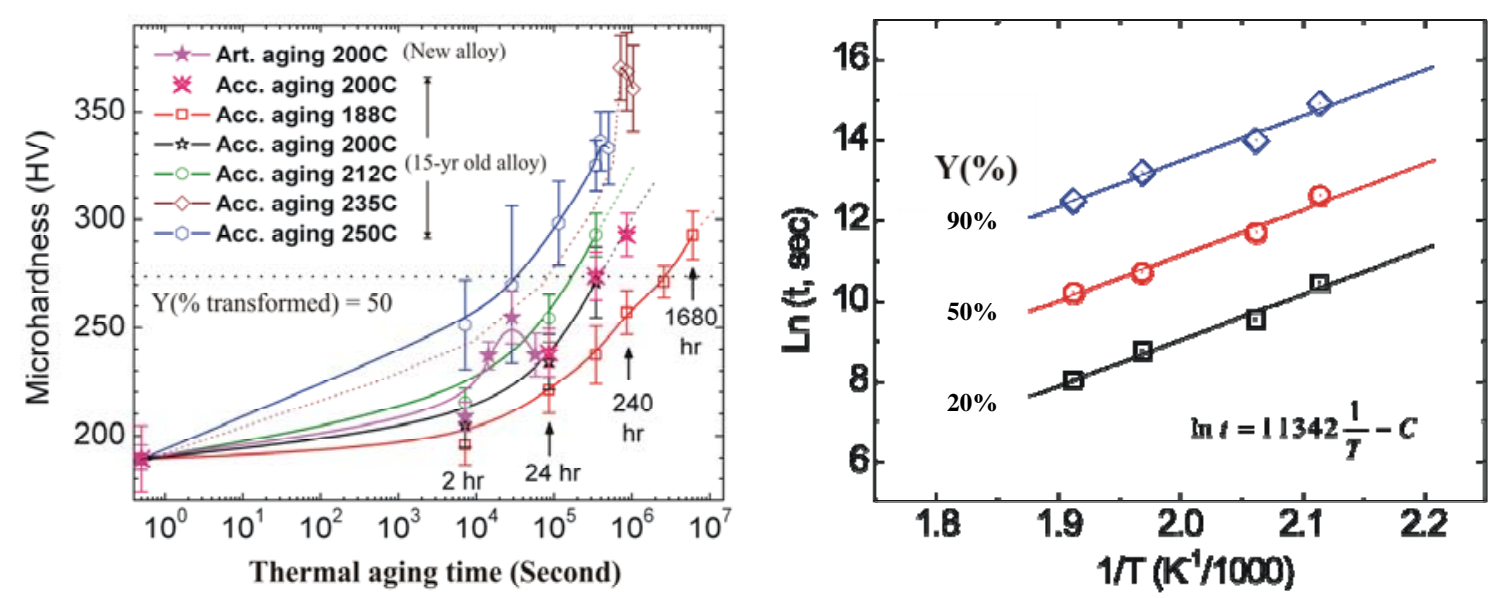

Fig. 8. (a) Microhardness curves obtained from the 15-year old alloys thermally aged at temperatures between $188{ }^{\circ} \mathrm{C}$ and $250{ }^{\circ} \mathrm{C}$ and (b) a linear equation: $\ln t=11342 \frac{1}{T}-C$ was derived from a $\ln \mathrm{t}$ vs. $1 / \mathrm{T}$ plot for different $\mathrm{Y}(\%)$.

Table 2 Life-time prediction for the percentage transformed of the 15-year old alloy at temperatures below $100{ }^{\circ} \mathrm{C}$.

\begin{tabular}{|c|r|r|r|r|r|}
\hline \multirow{2}{*}{$\begin{array}{c}\text { Temperature } \\
(\end{array}$} & \multicolumn{5}{|c|}{ Years to be transformed by } \\
\cline { 2 - 6 } & $\mathbf{2 0 \%}$ & $\mathbf{2 5 \%}$ & \multicolumn{1}{c|}{$\mathbf{5 0 \%}$} & \multicolumn{1}{c|}{$\mathbf{8 0 \%}$} & \multicolumn{1}{c|}{$\mathbf{9 0 \%}$} \\
\hline $\mathbf{3 0}$ & 576.1 & 1095.2 & 5567.5 & 29310.6 & 58000.3 \\
\hline $\mathbf{5 0}$ & 57.3 & 107.9 & 548.3 & 2886.8 & 5712.5 \\
\hline $\mathbf{7 5}$ & 4.6 & 8.7 & 44.0 & 231.7 & 458.4 \\
\hline $\mathbf{1 0 0}$ & 0.5 & 1.0 & 5.0 & 26.1 & 51.6 \\
\hline $\begin{array}{l}\text { Ductility } \\
\text { reduction (\%) }\end{array}$ & - & - & $\sim 65$ & & \\
\cline { 1 - 6 } & & & &
\end{tabular}

\section{Conclusion}

Precipitation kinetics of a 15 -year old WQ-U6Nb alloy containing partially ordered $\alpha^{\prime \prime}$ po phase was studied using microhardness measurement of the alloy thermally aged at temperatures between $188{ }^{\circ} \mathrm{C}$ and $250{ }^{\circ} \mathrm{C}$ in order to develop an empirical time-temperature-transformation model for predicting the remaining lifetime of the WQ-U6Nb alloy in the stockpile. The microhardness increases as a result of the occurrence of decomposition reaction: $\alpha^{\prime \prime}{ }_{\mathrm{po}} \rightarrow \alpha(\mathrm{U})+\alpha_{\mathrm{o}}\left(\mathrm{U}_{3} \mathrm{Nb}\right)$ during thermal aging of the 15 -year old 
alloy. The percentage transformed, $\mathrm{Y}(\%)$, of the alloy was approximately measured from the change of microhardness according to law of mixtures: $\mathrm{H}_{t}=\mathrm{H}_{m} V_{m}+\mathrm{H}_{\mathrm{p}} \mathrm{V}_{\mathrm{p}}$ and $\mathrm{V}_{\mathrm{m}}+\mathrm{V}_{\mathrm{p}}=1$. The microhardness of the transformed alloy increases proportionally with the increasing volume of precipitates and reaches a maximum value when the alloy contains a maximum volume fraction $(\sim 56 \%)$ of $\mathrm{U}_{3} \mathrm{Nb}$ precipitates; the microhardness starts to decrease when coarsening of the precipitates starts. Thus, the percentage transformed, $\mathrm{Y}(\%)$, is approximately evaluated as: $\mathrm{Y}(\%) \approx\left[\left(\mathrm{H}_{\mathrm{t}}-\mathrm{H}_{0}\right) /\left(\mathrm{H}_{\mathrm{f}}-\mathrm{H}_{0}\right)\right]$.

The low-temperature kinetics of precipitation reaction were empirically modeled using Avrami equation: $\mathrm{Y}=1-\exp \left(-\mathrm{Kt}^{\mathrm{n}}\right)$, and $\mathrm{K}=\mathrm{C}_{0} \exp \left[-\left(\Delta \mathrm{G}_{\mathrm{a}}+\Delta \mathrm{G}_{\mathrm{c}}\right) / \mathrm{kT}\right]$ together with a graphical meathod to determine the diffusion energy for diffusion $\left(\Delta \mathrm{G}_{\mathrm{a}}\right)$ from an inverse time-temperature-transformation plot. The activation energy diffusion was evaluated to be $22.5 \mathrm{kcal} / \mathrm{mol}$, and the life-time of the 15 year old WQ-U6Nb alloy thermally aged at temperatures below $100^{\circ} \mathrm{C}$ were accordingly evaluated.

\section{Acknowledgements}

This work was performed under the auspices of the U.S. Department of Energy by Lawrence Livermore National Laboratory under Contract DE-AC52-07NA27344. The authors gratefully acknowledges Dr. T. C. Sun for the work of tensile ductility experiment, Dr. C. Saw for the work of xray diffraction analysis, Roger Krueger for the work of aging experiment, Vicki Mason-Reed for the work of optical metallography, and Rick Gross for the preparation of TEM foils.

\section{References}

1. L. Hsiung and J. Zhou, "Spinodal Decomposition and Order-Disorder Transformation in a WaterQuenched U-6wt.\%Nb Alloy,” LLNL Report, UCRL-TR-224432 (2006).

2. J. Burke, "The Kinetics of Phase Transformations in Metals," Pergamon Press, London (1965).

3. M. Avrami, J. Chem. Phys., 7, p. 1103 (1940).

4. J. W. Christian, Chapter 12 in "Transformations in Metals and Alloys," Pergamon Press, New York, p. 525 (1981). 